\title{
Real Time Total Productive Maintenance System
}

\author{
Özge Kart, Alp Kut \\ Dokuz Eylul University, Izmir, Turkey
}

\begin{abstract}
In today's industrial environment big losses happen in manufacturing sector. These losses may be because of tooling issues, process, operators, maintenance personnel, and non-availability of components on time and so on. Zero situated ideas, for example, zero tolerance for waste, defects, break down and zero accidents are turning into essential in the manufacturing and assembly industry. The objective of the Total Productive Maintenance $(T P M)$ is to enhance productivity and quality alongside improved employee morale and job satisfaction. This study aims to develop web based software for handling fundamental TPM pillars. Furthermore, real time production data are transferred from manufacturing machines to the system via a data collection device and monitored on dashboards.
\end{abstract}

\section{Introduction}

Emerging trends show that, commonly, numerous manufacturing systems being used are not performing as expected, so far as cost effectiveness regarding their operation and support is concerned. Some of them frequently perform less than whole capacity, with low productivity, and the cost of production items are high. Actually, these costs are depended to maintenance work and materials. Maintenance has an important effect on keeping and enhancing availability, product quality and safety requirements. As a result of the support and maintenance problems experienced in manufacturing, the Japanese created and presented the idea of total productive maintenance (TPM). Total Productive Maintenance [1] is a productivity management system. It was put forward in 1970's by reformatting Preventive Maintenance (PM) Principles which is very popular in USA in 1950's.

Motivation of this study is to develop a proper and practicable software project (Real Time Total Productive Management/RTPM) to solve a common real world problem. The purpose of the project is developing software and using for implementing TPM activities [2,3,4] such as Autonomous Maintenance, 5S, Education and Training, Kaizen on electronic environment. The project also contains OEE (Overall Equipment Effectiveness) computation module. The production data is provided by hardware units. These hardware units are developed in the project for collecting production data simultaneously and transferring to the system. Dashboards show real time production data with this mechanism. Real time production status can be monitored from dashboards in web or mobile web platforms.

This is an ongoing study supported by The Scientific and Technological Research Council of Turkey. Dokuz Eylul University Department of Computer Engineering academicians and an IT Company, which is in small and medium-sized enterprise (SME) status, carries out the study in collaboration.

The developed software contains several modules and sub-activities. These modules and sub-activities require researching in different technology areas. Integration schema of these modules is shown in Figure 1.

\section{Related Work}

Thota and Dwivedi characterized TPM in point of interest, assessed its potential as a maintenance science and its effective usage bringing about reliable production equipment. Definite stress was provided for the interrelated ideas of TPM and Lean manufacturing and the basic focuses of cost reduction, upgraded quality, adaptability and durability, time variables and employee participation, equipment performance were handled well. Hence an imaginative period of planning and preventing repeating costs on machines were decreased leading to continuous operation of equipment.[3]

Chan et. Al. aimed to study the effectiveness and troubles experienced in an electronics manufacturing organization throughout the TPM usage and likewise the real success factors that help the accomplishment of TPM. The aim of the study was the realization of TPM and the assessment of its result on model machine in front-end segment, Automated Assembly Department. At the end of the study, equipment productivity increased $83 \%$ after TPM usage. Likewise, the equipment stoppage rate was diminished from 517 to 89 times. This huge change improved the equipment in both effectiveness and quality in product. [1]

Prasanna, Ramesh, and Arunkumar did a useful study in a tire fabricating Industry where one of the 


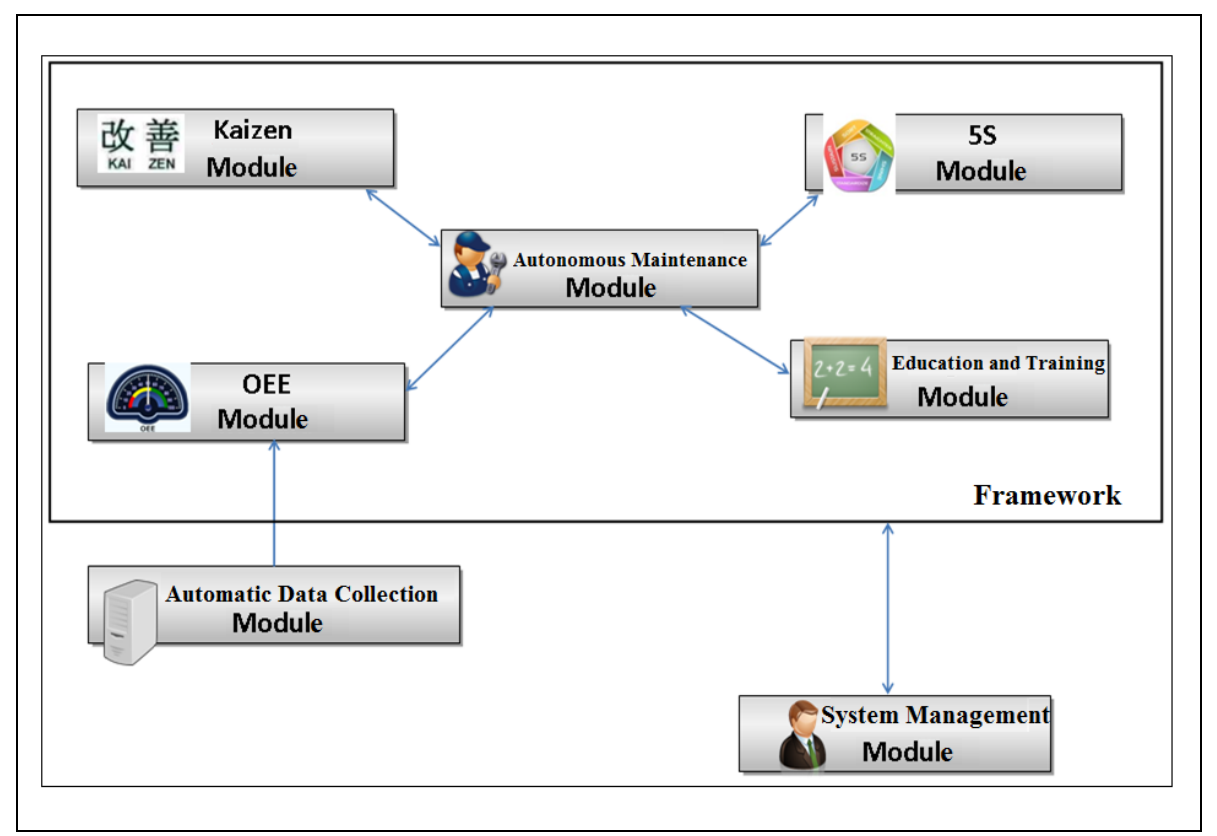

Figure 1. Modules integration scheme

fundamental issues of Total Productive Management (TPM) is consumed as it is a basic extra to lean manufacturing. In their study, execution of Kaizen has lessened the amount of events of altering the conveyer belt tension from existing 20 minutes for every day. to twice a week and additionally made the operation simple. This has decreased the man hour loss \& production loss bringing about enhanced productivity. By realizing Kaizen 4 Roll calendar equipment availability for production has enhanced, thusly OEE (over all equipment efficiency) has increased significantly. Further, Kaizen usage has brought about the decrease of idle man hours and machine hours.[5]

Singh et. Al. shared the experience of implementing Total Productive Maintenance. They researched TPM for an organization manufacturing automotive segment. Idea was applied to the machine shop having CNC turning units of different limit. Overall Equipment Effectiveness (OEE) was utilized as the measure of achievement of TPM usage. The losses about equipment effectiveness were recognized. All the pillars of TPM were applied in a staged way minimizing the losses and consequently enhancing the use of $\mathrm{CNC}$ machines. [2]

Holmgren aimed to determine the losses associated with maintenance to clarify deviations in the maintenance process that contribute to accidents and incidents. The study demonstrated that maintenance related accidents covers $30 \%$ of all track related incidents and accidents. The most common reason for maintenance related accidents is insufficient communication between maintenance personnel and the operators. The result of the study indicates that Total Productive Maintenance is essential for companies. [6]

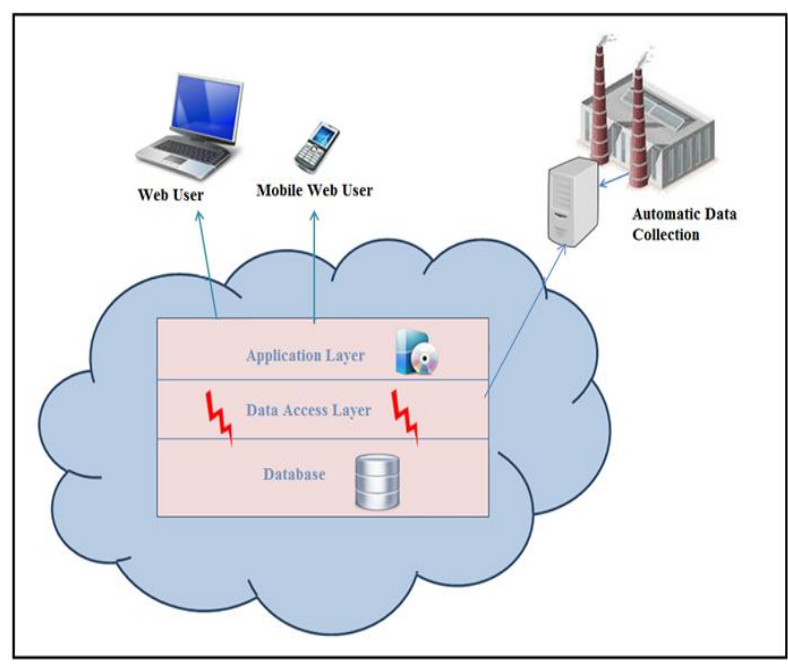

Figure 2. System architecture

\section{Material and Method}

The study involves developing a web application for web and mobile web users. An automatic data collection unit is developed and integrated to the system as well. Architectural structure of the project is represented schematically in Figure 2.

\subsection{Software Framework}

At the beginning of the work, a software framework is developed as a basis for project modules. The framework includes common functions 
required for the software and also helps to build user interfaces more easily. It provides software reuse, standard coding and less error in coding.

\subsection{Autonomous Maintenance}

The Autonomous Maintenance is set of activities which aim to make each worker does cleaning, control, basic repair, problem solving, validation control etc. on his own equipment. Autonomous maintenance is central module of other TPM modules as well. All other modules are associated with Autonomous Maintenance.

Problem statement, approval and improvement processes, creating suggestion cards or negativity cards and monitoring them in electronic environment are the activities located in this module. There is also a scoring mechanism for the employees who create cards and solve the problems.

Committee members' management system, in which the committee members do task assignment and evaluation, is implemented. Reports about meeting decisions are prepared in specified format.

Detailed activities implemented in Autonomous Maintenance are listed below:

1. Positive scoring

Main goal of Autonomous Maintenance is improving motivation of employees with rewarding mechanism. Employees gain some points when they create following notifications. When score of an employee reaches some specific levels, he gains various awards.

The following notifications are created by employee and recorded to the system.

2. Negativity Notification: Notification of negativity in manufacturing plant or office area about equipment, tools, machines or processes,

3. Suggestion Notification: Notification of suggestion about any productivity related improvement.

4. Near Miss Notification: Notification of potentially dangerous malfunctions or situations in manufacturing plant about equipment, tools, machines or processes. All near miss cases have emergency and must be handled as soon as possible. The system alerts TPM committee about unhandled near miss cases on time.

5. Pollution Source Notification: Detection of high level pollution source.

6. Notification of Hard to Reach Areas: Detection of problems in hard to reach areas.

All these notifications are evaluated by TPM commitee which consists of high level managers including general manager.

7. Sharing Responsibility

In Sharing Responsibility the main idea is transferring periodical maintenance operations on equipment to related employee instead of maintenance team. For the implementation of this idea, One Point Lesson technique may also be used.

8. TPM Committee Operations

A TPM committee manages all TPM activities. The aim of this module is creating a TPM committee, adding members to the committee and managing members. Head of the committee must be CEO of the company.

TPM committee operations can be listed as follows:

- Periodic TPM meetings are planned. In these meetings all TPM activities happened in time period are discussed by the TPM committee. Sub committees and teams may be created. Tasks are distributed to the sub committees or teams.

- Negativity notifications and suggestions may trigger other TPM activities such as Kaizen or Education and Training as a result of committee's evaluations.

In TPM process, motivating employees by rewarding mechanism is essential. On the other hand, there are no penalty points. Each personnel can see how much points he/she has and which prize is closer to him/her from the system.

\subsection{S (Seiri-Sort, Seiton- Set in Order, Seiso-Shine, Seiketsu-Standardize, Shitsuke- Sustain)}

This module takes its name from the first Japanese characters of five steps which construct the system. The goals of the 5S methodology are decreasing error rate, increasing productivity and quality, reducing cost, decreasing setup time, improving motivation and communication, early detection of problems and creating pleasant working environment [7].

Steps of 5S:

- Seiri (Sort) is the first step of $5 \mathrm{~S}$ activities. It means sorting items that are convenient and nonconvenient by marking those using labels. Non convenient stuff is removed from the workplace.

- Seiton (Set in Order) is the second step after sorting. Aim of Seiton is arranging convenient stuff that simple, safe and given constraints.

- Seiso (Shine) is cleaning environment and parts of equipments.

- Seiketsu (Standardize) means standardizing Seiri, Seiton, Seiso steps.

- Shitsuke (Sustain) means sustaining other four steps by making employees followed the guidelines and safety precautions during their work.

Implementation methods of each S Step:

1. Planning: The location, machine or equipment on which $5 \mathrm{~S}$ activities applied is defined. Activity plans are also defined. Evaluation questions which will be handled at the end of term are entered to the system in advance. 
2. Inspection: End of term evaluation results are stored in the system.

3. Scoring: The employees involved in any step of a $5 \mathrm{~S}$ process gain points. Extra points are given to the employees who become " $5 \mathrm{~S}$ of the month".

4. Proceeding to next step:_After completing a step, inspection and evaluation processes are executed by TPM committee. If the committee approves the improvements, the $5 \mathrm{~S}$ team is proceeded to next step.

\subsection{Education and Training}

Aim of education and training module is making operators educated through TPM activities. The activities which are implemented within this module are as follows: identifying educational shortcomings, preparing one point lessons, teaching one point lessons, preparing vocational training, teaching vocational training, taking reports on educational activities.

Information about the lessons and trainings such as who prepare the content or who take them is recorded to the system and may be managed. Each personnel involved in an education and training process gain points.

\subsection{OEE (Overall Equipment Effectiveness)}

OEE Module contains operating times, stop times and other measurements about OEE in dashboards. The central issue of this module is showing real time data on dashboards through an automatic data collection unit. OEE Formula is:

Availability $=$ Operating Time $/$ Planned Production Time

Performance $=($ Parts Produced $*$ Ideal Cycle Time $) /$ Operating time

Quality = Good Pieces / Total Pieces

$\mathrm{OEE}=$ Availability $\mathrm{x}$ Performance $\mathrm{x}$ Quality

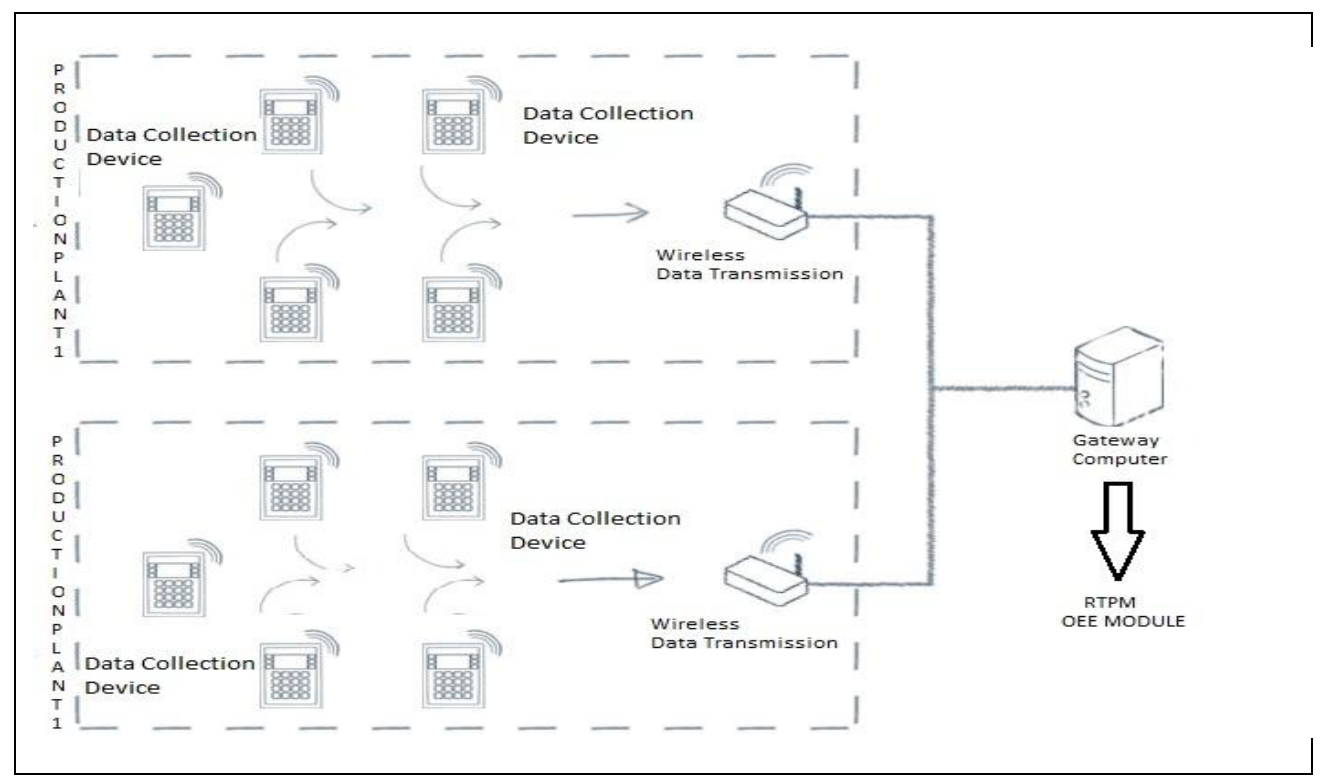

Figure 3. Data collection and transmission system

\subsection{Automatic Data Collection}

In Automatic Data Collection module, production data is collected from production lines automatically and transferred to the main system. The collected data is used in OEE calculation and instant productivity monitoring. The data collection hardware has sensors for counting products during manufacturing process. These sensors may use technologies such as motion detection, metal detection etc. Each terminal has capabilities for counting and accumulating real time production information and also has capabilities for sending information to Gateway Computer using a central wireless data transmission unit (Figure 3). This data transmission is confirmed using a handshaking mechanism, if any problems detected the buffered information will be retransmitted using same mechanism.

This module provides:

- Real time process monitoring,

- saving time by eliminating manual data entries,

- showing instant production information on dashboards,

- collecting real time data for correct OEE calculation. 


\subsection{Kaizen}

Kaizen means "Continuous Improvement" [7]. The basis of Kaizen is small-sized, continuous improvements done by especially employees for enhancing working conditions or decreasing costs in manufacturing plants or offices. Kaizen has two subtopics:

\subsubsection{Before After Kaizen}

In Before After Kaizen processes, date and location of improvement, problem definition, proposed solution, related employees and photographs of before and after situations of the enhanced location are created and managed.

1. Determining the initial state

Related personnel information, problem definition, location of the problem, entry date, and photograph of initial state is recorded to the system.

2. Approval of problem and determining solution

Reported problem is discussed by TPM committee. If it is decided to be a Kaizen, committee assigns tasks to related employees for solving the problem.

3. Implementation and documentation of solution

Determined solution is implemented. After improvement, photograph of Kaizen location is recorded to the system to compare with the initial state.

\subsubsection{Kobetsu Kaizen}

Kobetsu Kaizen means systematic improvements achieved by making analysis for decreasing the losses related to material, energy, equipment and manpower on the long view. Kobetsu Kaizen operations consist of 5 steps:

1. Preparing Kobetsu Kaizen Form

Specifications of Kaizen, working model and problem areas are defined in this form. Kaizen personnel team(s) is generated and stored in the form as well.

\section{Defining Losses}

One or more losses are defined among manpower, energy, equipment and material losses for implementing Kobetsu Kaizen. These losses are also stored in system.

3. Establishing themes and planning

Specific solution theme is established to prevent defined losses.

\section{Kaizen Implementation}

According to prepared plan in previous step, related activities are defined and verified. Finally, Kaizen implementation is completed.
5. Effectiveness Control and Approval

After completing related Kaizen activity, the results of improvement are checked by the TPM committee. If the improvement is successful, related Kaizen team gain points.

\section{Conclusion and Future Work}

TPM system is a productivity management system created by Japanese to improve productivity and quality. It aims to improve employee morale and job satisfaction as well. The purpose of this study is developing a software and using it for implementing fundamental TPM activities on electronic environment. In the project, also hardware units are developed for collecting production data from manufacturing plant to show instant productivity. After completion, results of the study will be analyzed and published.

As a future work, 6 Sigma and Kanban principles may be integrated to the system. The project may be transferred to a cloud based environment. This model can provide to SME's easy to use, scalable, low cost software solution [8].

\section{References}

[1] F.T.S. Chan, H.C.W. Lau, R.W.L. Ip, H.K. Chan, S. Kong, " Implementation of total productive maintenance: A case study", Int. J. Production Economics 95,71-94, 2005

[2] R. Singh, A. M. Gohil, D. B. Shah, S. Desai, "Total Productive Maintenance (TPM) Implementation in a Machine Shop: A Case Study", Chemical, Civil and Mechanical Engineering Tracks of 3rd Nirma University International Conference on Engineering, 2013

[3] R. Thota, N. Dwivedi, "Total Product Maintenance in Lean Manufacturing”, ASEE Gulf-Southwest Annual Conference, 2006

[4] P. Raymond, J. Lizotte, "Using The Total Productive Manufacturing (Tpm) Model To Drive To A Higher Level Of Pollution Prevention", IEEE International Symposium on Electronics and the Environment, 1999

[5] N. Prasanna, V. Ramesh and D. Arunkumar, "Modern methods to solve Industry Problems A Lean Management Case Study carried out in a Processing Industry", International Computer Science and Technology Conference, 2008

[6] M. Holmgren, "Maintenance Related Losses", Dissertation, Lulea University of Technology, 2003

[7] M. A. Titu; C. Oprean, D. Grecu, "Applying the Kaizen Method and the 5S Technique in the Activity of Post-Sale Services in the Knowledge-Based Organization", International Multi Conference of Engineers and Computer Scientists, Vol III, 2010

[8] Y. Gong, Z. Ying, M. Lin, “A Survey of Cloud Computing", GCN 2012, Lecture Notes in Electrical Engineering Volume 225, pp 79-84, 2013 